\title{
Ocorrência de Sclerotinia sclerotiorum (Lib.) de Bary em Aster ericoides L. (White Show) no estado de São Paulo, Brasil.
}

\author{
César Júnior Bueno ${ }^{1}$, Márcia Michelle de Queiroz Ambrósio² e Nilton Luiz de Souza ${ }^{2,3}$
}

${ }^{1}$ Pesquisador Científico I - APTA Regional Extremo Oeste - Av. Alcides Fagundes Chagas, 122, CEP 16055-240, Araçatuba-SP, e-mail: cjbueno@aptaregional.sp.gov.br; ${ }^{2}$ Faculdade de Ciências Agronômicas - UNESP, CP. 237, 18603-970, Botucatu-SP; ${ }^{3}$ Bolsista do CNPq. Autor(a) para correspondência: César Júnior Bueno.

Data de chegada: 20/06/2005. Aceito para publicação em: 25/10/2005

A planta Aster ericoides L. da família Asteracea, originária da América do Norte, é muito cultivada em jardins, vasos ou como flores de corte. É uma planta perene, com rizomas e estolhos amplos e com flores diminutas nas partes terminais das ramificações, semelhantes a pequenas margaridas.

A Holanda é o maior mercado mundial de flores e atingiu a venda de 60 milhões de hastes florais anuais em 1994. No Brasil, há um potencial para a expansão no cultivo do aster e os consumidores preferem os cultivares com flores brancas para arranjos florais (Camargo, M.S. Nutrição e adubação de Aster ericoides (White Master) influenciando produção, qualidade e longevidade. 2001. 107 f. Tese-Esalq/USP, Piracicaba, 2001).
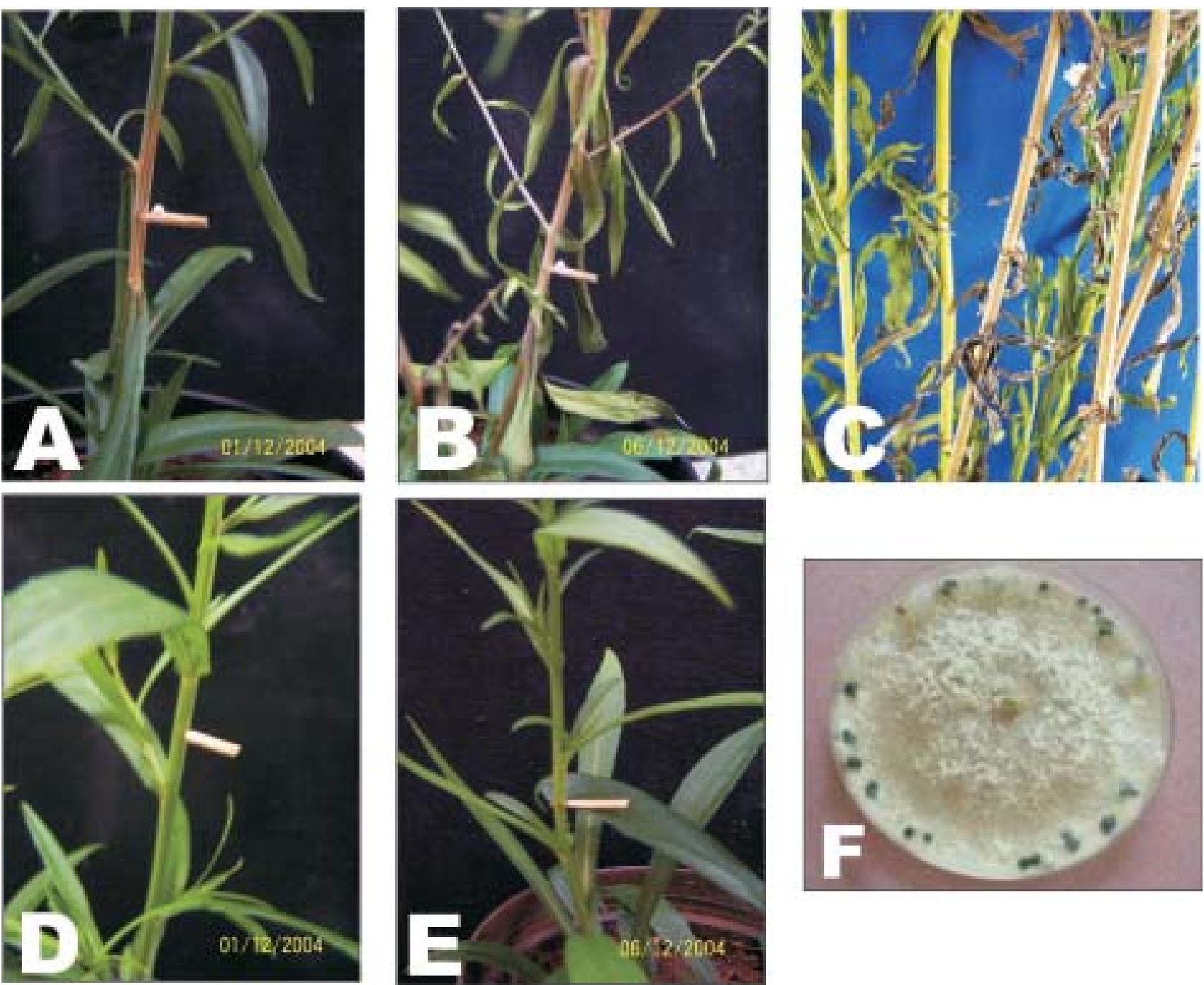

Figura 1. Dois dias de avaliação mostrando a evolução dos sintomas da doença nas plantas inoculadas artificialmente (A e B) e no tratamento testemunha (DeE). Planta com sintoma natural da doença (C) e o fungo isolado em meio de BDA (F). 
O fungo Sclerotinia sclerotiorum (Lib.) de Bary é de ampla ocorrência, muito agressivo e causa sintomas em diversas partes da planta (Bueno, C.J. Produção e preservação de estruturas de resistência de fungos fitopatogênicos habitantes do solo. 2004. $101 \mathrm{f}$. Tese. FCA/UNESP, Botucatu, 2004). Os sintomas característicos da doença são a necrose no caule (ou haste) e murchamento seguido da seca das folhas, enquanto que os sinais são o crescimento de micélio cotonoso e branco na superfície dos tecidos lesionados e a presença de inúmeros escleródios pretos e grandes (Kimati et al. Manual de Fitopatologia: doenças das plantas cultivadas. 3 ed. São Paulo: Agronômica Ceres, 1997. 774p.).

Em uma propriedade agrícola, localizada no município de AvaréSP, plantas de Aster ericoides L. (White Show) foram detectadas com sintomas de necrose de cor pardoesbranquiçada na haste e presença de folhas amareladas, murchas e secas. Procedeu-se o isolamento do agente causal da doença em meio de cultura BDA (Batata Dextrose Agar) + $0,05 \mathrm{mg} \cdot \mathrm{mL}^{-1}$ de oxitetraciclina. Após o crescimento do patógeno, o mesmo foi identificado como o fungo Sclerotinia sclerotiorum com base nas características morfológicas e presença de inúmeros escleródios pretos e grandes nas bordas das colônias (Figura 1F). Testes de patogenicidade foram realizados em mudas de Aster ericoides L. (White Show), por meio da introdução de um palito de madeira (tipo "palito de dente"), infestado ou não pelo fungo, nas hastes das plantas
(Ferraz, L.C.L. Biologia de Sclerotinia sclerotiorum e aspectos de controle cultural de mofo-branco em feijoeiro. 1996. $202 \mathrm{f}$. Dissertação - Faculdade de Agronomia e Medicina Veterinária, UnB, Brasília, 1996.). Foram feitas seis repetições, sendo cada vaso (parcela) constituído por uma planta contendo três hastes (uma principal e duas secundárias). No tratamento testemunha, cada haste das plantas recebeu um palito de madeira não infestado pelo fungo. As plantas foram dispostas inteiramente casualizadas dentro de estufa tipo BOD a temperatura de $26^{\circ} \mathrm{C}$, em condições de câmara úmida e com fotoperíodo de 12 horas de luz e 12 horas de escuro. A avaliação consistiu na visualização dos mesmos sintomas observados nas plantas do município de Avaré-SP. Os primeiros sintomas foram observados três dias após a inoculação das plantas (Figura 1A). Os sintomas foram semelhantes aos observados nas plantas infectadas naturalmente (Figura 1C). O fungo foi reisolado das lesões obtidas da inoculação artificial, finalizando assim os postulados de Kock e confirmando sua atuação como agente causal da doença.

No mundo temos relatos da ocorrência do fungo em plantas (Takeuchi, J. \& Horie, H. First occurrence of Sclerotinia rot in Aster and strawflower in Japan. Annual Report of the Kanto Tosan Plant Protection Society, Tokyo, v. 46, p.57-59, 1999) e em sementes de Aster spp. Esta é a primeira descrição da ocorrência de Sclerotinia sclerotiorum (Lib.) de Bary em plantas de Aster ericoides L. (White Show) no Brasil. 